\title{
REVIEW
}

\section{Tricyclic antidepressant overdose: a review}

\author{
G W Kerr, A C McGuffie, S Wilkie
}

\begin{abstract}
Overdoses of tricyclic antidepressants are among the commonest causes of drug poisoning seen in accident and emergency departments. This review discusses the pharmacokinetics, clinical presentation and treatment of tricyclic overdose. (Emerg Med f 2001;18:236-241)
\end{abstract}

Keywords: tricyclic antidepressant; overdose

The first report of the adverse effects of tricyclic overdose was in 1959 and came within two years of their clinical usefulness having been recognised. ${ }^{1}$ Now tricyclics are identified as one of the most frequently ingested substances in self poisoning along with paracetamol, benzodiazepines and alcohol. ${ }^{2}$ They are second only to analgesics as the commonest drug taken in fatal drug overdose. ${ }^{34}$ There is also evidence that the number of deaths relative to the number of prescriptions issued is significantly higher for tricyclics in comparison to other antidepressants. ${ }^{5}$

On average 268 people in Britain die each year after taking an overdose of tricyclic drugs. ${ }^{5}$ Despite the introduction of newer and safer antidepressants the prescription of tricyclics is still widespread as they are cheaper and many still consider them to be the most effective group of antidepressants.

The commonest tricyclic taken in fatal overdose is dothiepin, ${ }^{5}$ which, along with amitriptyline, has been shown to have comparatively greater toxicity than other tricyclics. ${ }^{56}$

Accident and
Emergency
Department,
Crosshouse Hospital,
Kilmarnock
A C McGuffie
S Wilkie
Correspondence to:
Dr Kerr
(gary.kerr@aaaht.scot.nhs.uk)
Accepted for publication
26 September 2000

\section{Pharmacokinetics}

Tricyclics are rapidly absorbed from the gastrointestinal tract and undergo first pass metabolism. They are highly protein bound and have a large volume of distribution, resulting in a long half life of elimination that generally exceeds 24 hours and in the case of amitriptyline is 31 to 46 hours. $^{7}$ After metabo-

Table 1 Clinical features and complications of tricyclic antidepressant overdose

\begin{tabular}{lll}
\hline Cardiovascular system & Central nervous system & Anticholinergic effects \\
\hline Sinus tachycardia & Drowsiness & Dry mouth \\
Prolonged PR/QRS/QT & Coma & Blurred vision \\
ST/T wave changes & Convulsions & Dilated pupils \\
Heart block & Pyramidal signs & Urinary retention \\
Vasodilatation & Rigidity & Absent bowel sounds \\
Hypotension & Delirium & Pyrexia \\
Cardiogenic shock & Respiratory depression & Myoclonic twitching \\
Ventricular fibrillation/tachycardia & Ophthalmoplegia & \\
Asystole & & \\
\hline
\end{tabular}

lism by hepatic enzymes the metabolites, some of which have pharmacological activity themselves, are conjugated and excreted by the kidneys.

The ingestion of large quantities of tricyclics in self poisoning causes altered pharmacokinetics. ${ }^{8}$ Gastrointestinal absorption may be delayed because of inhibition of gastric emptying and significant enterohepatic recirculation prolongs the final elimination. The amount of unbound tricyclic may also increase if the overdose causes respiratory depression resulting in an acidosis, which reduces protein binding.

The toxic effects of tricyclics are caused by four main pharmacological properties:

1 Inhibition of norepinephrine reuptake at nerve terminals.

2 Direct $\alpha$ adrenergic block.

3 A membrane stabilising or quinidine-like effect on the myocardium.

4 Anticholinergic action.

\section{Clinical features}

The dose ingested, even if reliably confirmed, is a poor predictor of the subsequent clinical outcome. Doses of less than $20 \mathrm{mg} / \mathrm{kg}$ are unlikely to be fatal or cause severe complications ${ }^{9}{ }^{10}$ but individual variation in absorption, protein binding and metabolism limit any meaningful prediction.

The clinical features of tricyclic overdose can be grouped according to their effects on the peripheral autonomic system (anticholinergic effects), the cardiovascular system and the central nervous system (table 1).

\section{ANTICHOLINERGIC EFFECTS}

Anticholinergic features are common and may aid diagnosis in certain patients. Generally anticholinergic effects do not cause serious clinical problems but cases of toxic megacolon and intestinal perforation have been described. ${ }^{11}{ }^{12}$

By impairing sweating heat dissipation is reduced and this can result in a fever, especially if seizures occur. Central cholinergic block can also alter thermoregulation. ${ }^{13}$

\section{CARDIOVASCULAR EFFECTS}

The commonest cardiovascular effect is a sinus tachycardia, which is attributable to the inhibition of norepinephrine reuptake and the anticholinergic action. However, the most important toxic effect of tricyclics is the slowing of depolarisation of the cardiac action potential by inhibition of the sodium current 
and this delays propagation of depolarisation through both myocardium and conducting tissue. ${ }^{14}$ This results in prolongation of the QRS complex and the PR/QT intervals with a predisposition to cardiac arrhythmias. This inhibition of sodium flux into myocardial cells can occur to such an extent that depressed contractility can result ${ }^{1516}$ and this, coupled with the reduction in peripheral resistance, contributes to hypotension.

The overall incidence of serious cardiovascular arrhythmias is low. In one series four patients from 153 admitted to an intensive care unit had either a nodal or ventricular arrhythmia $^{17}$ and only 3 of 225 patients admitted to another intensive care unit developed arrhythmias. ${ }^{18}$ Hypotension is more common with an incidence of $14 \%$ to $51 \%$ having been reported. ${ }^{19-21}$

\section{CENTRAL NERVOUS SYSTEM EFFECTS}

Coma was present in 53 patients $(17 \%)$ of a series of $316^{22}$ and the incidence is even higher $(52 \%)$ in the initial presentation of overdoses with a fatal outcome. ${ }^{23}$

Twenty four patients $(6.2 \%)$ from a series of 388 admitted to intensive care had seizures ${ }^{24}$ and confirmed a previous report of seizures exacerbating hypotension. ${ }^{25}$ This is thought to be caused by the metabolic acidosis associated with the seizures increasing the bioavailability of the tricyclic by decreasing the amount that is protein bound or altering the effect of tricyclics on the cardiac membrane sodium channels.

\section{Investigations}

Plasma tricyclic concentrations are not widely available and measured levels often lack sensitivity in detecting active metabolites. Petit et $a l^{26}$ demonstrated an increased incidence of seizures, coma and cardiac arrest in patients with a total tricyclic level greater than $1000 \mu \mathrm{g} / 1$ but subsequently it has been shown that prolongation of the QRS duration $(>0.16 \mathrm{sec}-$ onds) is a better predicator of seizures or ventricular arrhythmias than the plasma drug concentration. ${ }^{27}$ The QRS duration has also been associated with the probability of requiring ventilation ${ }^{18}$ but it is possible for a patient with very high plasma concentrations to have a normal QRS duration ${ }^{28}$ and the use of the QRS duration as a reliable indicator of poisoning severity is controversial. ${ }^{29}{ }^{30}$ Decreased R-R variation has been described as a method of identifying tricyclic overdose ${ }^{31}$ and it has been suggested that a terminal $\mathrm{R}$ wave greater than 3 $\mathrm{mm}$ in lead aVR is a more useful predictor of seizures or arrhythmias than QRS duration. ${ }^{32}$

The most frequent acid base disturbance is acidosis. ${ }^{33}$ This is often a mixed acidosis with both respiratory depression and myocardial impairment/hypotension resulting in reduced tissue perfusion and the production of lactate.

Hypokalaemia may be present and in a series of 295 patients $9 \%$ had a potassium concentration less than $3.0 \mathrm{mmol} / \mathrm{l}^{34}$

\section{Management}

REDUCING ABSORPTION

The majority of papers regarding gastric lavage include many different types of overdose substances. Kulig et al showed that lavage only improved clinical outcome in obtunded patients if performed within one hour of ingestion in a study of 592 poisoned patients. ${ }^{35} \mathrm{~A}$ subsequent study of over 800 patients failed to show any improvement in outcome from gastric lavage ${ }^{36}$ and it may even move ingested drug into the small bowel. ${ }^{37}$ The consensus statement of European toxicologists that gastric lavage should only be performed within one hour of the ingestion of a potentially life threatening dose is based on such papers. ${ }^{38}$

Where specifically tricyclic poisonings have been examined approximately $9 \%$ of the estimated ingested dose has been recovered ${ }^{39}$ but a comparison of gastric lavage and activated charcoal versus charcoal alone showed no difference in clinical outcome. ${ }^{40}$ There is no evidence to suggest that lavage should be considered outwith the one hour period in tricyclic poisoning.

Activated charcoal may reduce the absorption of tricyclics and the benefits of both single and multiple doses have been described. ${ }^{41}{ }^{42}$

Although Crome et al reported that a single dose of activated charcoal reduces absorption of tricyclics, the 12 subjects were given charcoal only 30 minutes after a therapeutic dose of nortriptyline. ${ }^{41}$ Others have also found a reduction when charcoal was given four hours after a therapeutic dose. ${ }^{43}$ However, studies of tricyclic overdoses involving 77 and 17 patients failed to show any reduction in systemic absorption after a single dose of charcoal. ${ }^{44}{ }^{45}$ It should be noted that doses of $20 \mathrm{~g}$ or $10 \mathrm{~g}$ of charcoal were used respectively.

Crome $^{41}$ and Karkkainen ${ }^{46}$ both studied the use of multiple dose activated charcoal in six patients and reported an acceleration of tricyclic elimination, but other small studies also involving therapeutic doses have failed to confirm this. ${ }^{47} 48$ Two studies reported on multiple dose regimens in a total of six tricyclic overdose patients and neither provides evidence to support a significant effect on elimination. ${ }^{4950}$

\section{ALKALINISATION}

The use of sodium bicarbonate in tricyclic poisoning has been shown to have beneficial effects. Brown et $a l^{11}$ successfully treated five children with tricyclic induced arrhythmias by administering boluses of sodium bicarbonate and subsequently they confirmed this antiarrhythmic action in experimental work with dogs. Further work with dogs has demonstrated a reduction in QRS duration, conversion of arrhythmias and a rise in blood pressure following sodium bicarbonate. ${ }^{52}$

In a review of 91 patients treated with sodium bicarbonate, hypotension was corrected in 20 of 21 patients $(96 \%)$ within one hour and QRS prolongation was corrected in 39 of 49 patients $(80 \%) .^{53}$ Similar effects have been described after alkalinisation by hyperventilation $^{5455}$ but the combined use of both 
techniques has resulted in profound alkalosis, which is associated with higher rates of mortality. ${ }^{56}$

The mechanism of this effect is a subject of debate. Brown et $a \bar{l}^{11}$ demonstrated that the plasma protein binding of amitriptyline increased with a more alkali $\mathrm{pH}$ and this was confirmed by a later study. ${ }^{57}$ This reduction in the pharmacologically active unbound fraction and a direct effect on myocardial contractility by correcting the metabolic acidosis present, were thought to be the causes. It is not surprising therefore that sodium bicarbonate has a therapeutic effect in patients with an acidosis. However, it has also been found to be effective in the absence of acidosis ${ }^{58}$ and even in a patient with a preceding alkalosis. ${ }^{60}$

The administration of hypertonic sodium chloride to rats with desipramine toxicity has been shown to be as effective as sodium bicarbonate in reversing QRS prolongation and hypotension while respiratory alkalosis had little effect. ${ }^{59}$ McCabe et al used a large animal swine model, which confirmed these findings and actually demonstrated that hypertonic saline had significantly more effect on these parameters than sodium bicarbonate. ${ }^{61}$ From these experiments it has been suggested that increasing the extracellular sodium concentration is the major mechanism. Other experimental work on the depolarisation of purkinje fibres has shown that the effects of increasing the extracellular sodium concentration and of raising the $\mathrm{pH}$ are distinct and additive. ${ }^{62}$

\section{ANTIARRHYTHMIC TREATMENT}

In general antiarrhythmic drugs should be avoided and the correction of hypotension, hypoxia and acidosis will reduce the cardiotoxic effects of tricyclics. Where antiarrhythmic agents are used it is important to avoid certain drugs that exacerbate the cardiac effects of tricyclics. Class 1a (quinidine, procainamide, disopyramide) and class 1c drugs such as flecainide, prolong depolarisation in a similar fashion to tricyclics. Likewise class 3 drugs (bretylium, amiodarone) also prolong the QT interval and may predispose to arrhythmias.

Lignocaine (lidocaine) has been reported as being effective in the treatment of frequent ventricular ectopics in 13 overdose patients but in some patients the ectopics persisted for up to 72 hours. $^{21}$ Experiments with four dogs failed to show any significant effect on the treatment of arrhythmias ${ }^{63}$ and other research with rats found that lignocaine only successfully treated one case from ten with tricyclic induced ventricular arrhythmias. ${ }^{64}$

Phenytoin is a class $1 \mathrm{~b}$ agent, which, unlike $1 \mathrm{a}$ and $1 \mathrm{c}$ drugs, can increase the rate of phase 0 depolarisation. Boehnert described the successful treatment of ventricular arrhythmias in three patients with the use of phenytoin. ${ }^{65}$ When phenytoin was used in a study of 10 patients it was found to correct conduction defects in five patients within 46 minutes and in the remaining five within 14 hours. ${ }^{66}$ However, these patients were stable with no arrhythmias and phenytoin did not change their clinical outcome. Animal experiments have failed to show any significant benefit from phenytoin in the prevention or management of arrhythmias. ${ }^{6367}$

The use of $\beta$ blockers may further reduce myocardial contractility and although reported as being effective in treating arrhythmias both in humans ${ }^{68}$ and animals, ${ }^{63}$ in all cases there was an marked decrease in blood pressure associated.

The use of glucagon in one patient was reported to increase blood pressure and reduce the QRS duration but sodium bicarbonate had also been given shortly before the glucagon. ${ }^{69}$ An animal experiment with glucagon found no beneficial effect on blood pressure or arrhythmias. ${ }^{63}$

Magnesium sulphate has been used successfully in an overdose patient with refractory ventricular fibrillation. ${ }^{70}$ Although an early experiment with two dogs found no benefit with magnesium, ${ }^{63}$ Knudsen reported that magnesium sulphate converted ventricular tachycardia to sinus rhythm in 9 of 10 rats. $^{71}$

Physostigmine is a short acting cholinesterase inhibitor that was proposed in the 1970 s as a treatment for arrhythmias. Since then, however, it has been described as causing asystole $^{72}$ and seizures. ${ }^{73}$ There is no role for its use in the management of tricyclic toxicity.

\section{HYPOTENSION}

Hypotension is thought to result from a combination of decreased myocardial contractility and peripheral vasodilatation. In cases refractory to the use of intravenous fluids the use of inotropic agents may be required. In theory pure $\alpha$ agonist agents should be used to avoid unopposed $\beta$ receptor stimulation. ${ }^{74}$

Norepinephrine has been found to be more effective than dopamine in the management of hypotension, possibly as the effect of dopamine partially depends on the release of endogenous norepinephrine stores that are depleted in tricyclic overdose because of reuptake inhibition. ${ }^{75}$ A study with amitriptyline poisoned rats has suggested that the use of epinephrine is less likely to cause arrhythmias in comparison with norepinephrine. ${ }^{76}$ Its use may be preferable because this and further experiments have demonstrated an additional benefit from the combined use of sodium bicarbonate and epinephrine. ${ }^{77}$

Extracorporal circulation has been used in patients who have not improved with the use of inotropes ${ }^{78} 79$ and experimental work in pigs has demonstrated increased survival with this technique. $^{80}$

\section{CARDIAC ARREST}

Where patients have a cardiac arrest after ingestion of tricyclics recovery is possible even after prolonged resuscitation. Patients have recovered after three and five hours of external cardiac massage.$^{81-83}$ This may be attributable to metabolism and redistribution of the tricyclic during this time with a subsequent reduction of its effect on the myocardium. 
CNS COMPLICATIONS

Seizures are usually self limiting but where treatment is necessary benzodiazepines are the treatment of choice. ${ }^{9}$ Although some recommend the use of phenytoin its efficacy has never been proven ${ }^{67}$ and in a rat model was found to be of no benefit. ${ }^{84}$ Patients with decreased conscious level and respiratory depression may require intubation.

DRUG ELIMINATION

Tricyclic specific antibody fragments have been developed and their effectiveness at reversing cardiovascular toxicity in animals has been demonstrated by several studies. ${ }^{85} 86$ However, experimental work has shown that extremely large amounts are required and at present the use of Fab fragments is limited by cost and the possibility of renal toxic effects. A case report of their clinical use indicates an improvement in QRS and QT intervals but sodium bicarbonate had also been given. ${ }^{87}$

Tricyclics have a very large volume of distribution and this restricts the role of methods designed to increase drug clearance from the intravascular space. The treatment of eight patients with resin haemoperfusion removed no more than $3.1 \%$ of the estimated ingested dose $^{88}$ and others have also described how only small amounts of tricyclic are extracted by haemoperfusion. ${ }^{89}$ Other techniques such as forced diuresis, peritoneal dialysis and haemodialysis do not seem to be any better..$^{90}$

\section{MONITORING}

Several reports have found that all major complications will be apparent within six hours of ingestion ${ }^{239192}$ and that the incidence of late complications is extremely low. ${ }^{93}{ }^{94}$ It has been shown that arrhythmias do not occur after cardiovascular toxicity has resolved..$^{93}$ There have been reports of ventricular arrhythmias and fatalities occurring up to five days after ingestion but these events were in patients who displayed continuing signs of toxicity. ${ }^{96} 97$

Patients should have cardiac monitoring until the electrocardiogram has been normal for 12 to 24 hours. $^{98}$

\section{Conclusion}

It has been reported that the advice from the British poisons centres concerning the management of tricyclic overdose is not uniform. ${ }^{99}$ Differences in the management strategies of the poisons centres reflect the quality of the evidence available. There are limited data and much of the evidence quoted is derived from animal studies, case reports or small series of healthy subjects. The quality of this information results in variable interpretations and seems to cause some ambiguity in the advice given. In the absence of further evidence a consensus approach to the management of tricyclic overdose with national guidelines could avoid confusion when medical staff seek advice from the poisons centres.

Contributors

Gary Kerr initiated the review, performed the original literature search and wrote the first draft. Crawford McGuffie and Stew- art Wilkie undertook literature searchs, edited and wrote further art Wilkie undertook literature searchs, edited and wrote further
drafts. Gary Kerr, Crawford McGuffie and Stewart Wilkie drafts. Gary Kerr, Crawford McGuffie and Stewart Wilkie
edited and wrote the final draft. Gary Kerr will act as guarantor.

Funding: none.

Conflicts of interest: none.

\section{Appendix: management plan for} treatment of tricyclic overdose

1 Assess and treat $\mathrm{ABCs}$ as appropriate.

2 Examine for clinical features

Check urea and electrolytes-look for low potassium

Check arterial blood gases-look for acidosis

Perform electrocardiograph-look for $Q R S>0.16$ seconds

3 Consider gastric lavage only if within one hour of a potentially fatal overdose.

4 Give 50 grams of charcoal if within one hour of ingestion.

5 Give sodium bicarbonate $(50 \mathrm{ml}$ of $8.4 \%$ ) if:

a $\mathrm{pH}<7.1$

b RS $>0.16$ seconds

c Arrhythmias

d Hypotension

6 Arrhythmias: Avoid antiarrhythmics

Correct hypoxia, hypotension, acidosis, hypokalaemia

Give sodium bicarbonate.

7 Hypotension: Give intravenous fluids

Consider inotropes

8 Cardiac arrest: Prolonged resuscitation may be successful

9 Monitoring: Patients who display signs of toxicity should be monitored for a minimum of 12 hours.

1 Lancaster NP, Foster AR. Suicidal attempt by imipramine overdose. BMF 1959; 1:338-9.

2 Buckley NA, Whyte IM, Dawson AH, et al. Self-poisoning in Newcastle, 1987-1992. Med F Aust 1995;164:190-3.

in Newcastle, 1987-1992. Med F Aust 1995;164:190-3. in the Lothian and Borders region of Scotland (19831991). Hum Exp Toxicol 1994;13:401-6.

4 Coleridge J, Cameron PA, Drummer OH, et al. Survey of drug related deaths in Victoria. Med f Aust 1992;157:45962.

5 Henry JA, Alexander CA, Sener EK. Relative mortality from overdose of antidepressants. BMF 1995;310:221-4.

6 Buckley NA, Dawson AH, Whyte IM, et al. Greater toxicity in overdose of dothiepin than of other tricyclic antidepressants. Lancet 1994;343:159-62.

7 Hollister L. Antidepressants. In: Katzung BG, ed. Basic and clinical pharmacology. 3rd ed. Connecticut: Appleton and Lange, 1987:327-35.

8 Jarvis MR. Clinical pharmacokinetics of tricyclic antidepressant overdose. Psychopharmacol Bull 1991;27:541-50.

9 Crome P. Poisoning due to tricyclic antidepressant overdose. Clinical presentation and treatment. Med Toxicol 1986;1:261-85.

10 Spiker D, Biggs J. Tricyclic antidepressants (prolonged plasma levels after overdose). $¥ A M A$ 1976;236:1711-12.

11 McMahon AJ. Amitriptyline overdose complicated by intestinal pseudo-obstruction and caecal perforation. Postgrad Med $\mathcal{F} 1989 ; 65: 948-9$

12 Ross JP, Small TR, Lepage PA. Imipramine overdose complicated by toxic megacolon. Am Surg 1998;64:242-4.

13 Hantson P, Benaissa M, Clemessy J, et al. Hyperthermia complicating tricyclic antidepressant overdose. Intensive Care Med 1996;22:453-55.

14 Brennan FJ. Electrophysiological effects of imipramine and doxepin on normal and depressed cardiac purkinje fibers. Am f Cardiol 1980;46:599-606

15 Marshall JB, Forker AD. Cardiovascular effects of tricyclic antidepressant drugs: therapeutic usage, overdose, and

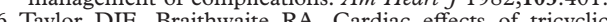
antidepressant medication: a preliminary study of antidepressant medication: a prelimin

17 Thorstrand C. Clinical features in poisonings by tricyclic Thorstrand C. Clinical features in poisonings by tricyclic
antidepressants with special reference to the ECG. Acta antidepressants with special

18 Hulten BA, Heath A. Clinical aspects of tricyclic poisoning. Acta Med Scand 1983; 213:275-8.

9 Frommer DA, Kulig KW, Marx JA, et al. Tricyclic antidepressant overdose. $\mathcal{F A M A}$ 1987;257:521-6.

20 Shannon M, Merola J, Lovejoy FH. Hypotension in severe tricyclic antidepressant overdose. Am f Emerg Med 1988;6: 439-42.

21 Langou RA, Van Dyke C, Tahan SR, et al. Cardiovascular manifestations of tricyclic antidepressant overdose. Am Heart $\mathcal{F}$ 1980;100:458-64.

22 Starkey IR, Lawson AAH. Poisoning with tricyclic and related antidepressants-a ten year review. Qf $\mathcal{F}$ Med 1980; related an

23 Callaham M, Kassel D. Epidemiology of fatal tricyclic antidepressant poisoning: implications for management. Ann Emerg Med 1985;14:1-9. 
24 Taboulet P, Michard F, Muszynski J, et al. Cardiovascular repercussions of seizures during cyclic antidepressant repercussions of seizures during cyclic antid.
poisoning. $\mathcal{F}$ Toxicol Clin Toxicol 1995;33:205-11.

25 Lipper B, Bell A, Gaynor B. Recurrent hypotension immediately after seizures in nortriptyline overdose. $A m \mathcal{F}$ Emerg Med 1994;12:452-3.

26 Petit JM, Spiker DG, Ruwitch JF, et al. Tricyclic antidepressant plasma levels and adverse effects after overdose. Clin Pharmacol Ther 1977;21:47-51.

27 Boehnert MT, Lovejoy FH. Value of the QRS duration versus the serum drug level in predicting seizures and ventricular arrhythmias after an acute overdose of tricyclic antidepressants. N Engl f Med 1985;313:474-9.

28 Marshall JB. Tricyclic overdose. FAMA 1980;244:1900.

29 Foulke GE, Albertson TE. QRS interval in tricyclic antidepressant overdosage inaccuracy as a toxicity indicator in emergency settings. Ann Emerg Med 1987;16:160-3.

30 Buckley NA, O'Connell DL, Whyte IM, et al. Interrater agreement in the measurement of QRS intreval in tricyclic antidepressant overdose: implications for monitoring and research. Ann Emerg Med 1996;28:515-19.

31 Rechlin T. Decreased R-R variation: a criterium for overdosage of tricyclic psychotropic drugs. Intensive Care Med 1995;21:598-601.

32 Liebelt EL, Francis PD, Woolf AD. ECG lead aVR versus QRS interval in predicting seizures and arrhythmias in acute tricyclic antidepressant toxicity. Ann Emerg Med 1995;26:195-201.

33 Thorstrand C. Clinical features in poisonings by tricyclic antidepressants with special reference to the ECG. Acto Med Scand 1976;199:337-44.

34 Strom J, Sloth Madsen P, Nygaard Nielsen N, et al. Acute self-poisoning with tricyclic antidepressants in 295 consecutive patients treated in an ICU. Acta Anaesthesiol Scand 1984;28:666-670

35 Kulig W, Bar-Or D, Cantrill SV, et al. Management of acutely poisoned patients without gastric emptying. Ann Emerg Med 1985;14:562-7.

36 Merigian KS, Woodard M, Hedges JR. Prospective evaluation of gastric emptying in the self-poisoned. Ann Emerg Med 1990;8:479-83.

37 Saetta JP, March S, Gaunt ME, et al. Gastric emptying procedures in the self poisoned patient: Are we forcing gastric content beyond the pylorus? F $R$ Soc Med 1991;84:274-6.

38 Anonymous. Position statement: gastric lavage. Clin Toxicol 1997;35:711-19.

39 Watson WA, Leighton J, Guy J, et al. Recovery of cyclic antidepressants with gastric lavage. F Emerg Med 1989;7:3737.

40 Bosse GM, Barefoot JA, Pfeifer MP, et al. Comparison of three methods of gut decontamination in tricyclic antidepressant overdose. F Emerg Med 1995;13:203-9.

41 Crome P, Dawling S, Braithwaite RA, et al. Effect of activated charcoal on absorption of nortriptyline. Lancet 1977;ii: $1203-5$.

42 Swartz C, Sherman A. The treatment of tricyclic antidepressant overdose with repeated charcoal. 7 Clin Psychopharmacol 1984;4:336-40.

43 Dawling S, Crome P, Braithwaite R. Effect of delayed administration of activated charcoal on nortriptyline absorption. Eur f Clin Pharmacol 1978;14:445-7.

44 Hulten BA, Adams R, Askenasi R, et al. Activated charcoal in tricyclic antidepressant poisoning. Hum Toxicol 1988;7: 307-10.

45 Crome P, Adams R, Ali C, et al. Activated charcoal in tricyclic antidepressant poisoning:pilot controlled clinical trial. Hum Toxicol 1983;2:205-9.

46 Karkkainen S, Neuvonen PJ. Pharmacokinetics of amitriptyline influenced by oral charcoal and urine $\mathrm{pH}$. Int $\mathcal{F}$ itriptyline influenced by oral charcoal Ther Toxicol 1986;24:326-32.

47 Scheinin M, Virtanen R, Iisalo E. Effect of single and repeated doses of activated charcoal on the pharmacokinetics of doxepin. Int $\mathcal{F}$ Clin Pharmacol Ther Toxicol 1985;23:38-42.

48 Goldberg MJ, Park GD, Spector R, et al. Lack of effect of oral activated charcoal on imipramine clearance. Clin Pharmacol Ther 1985;38:350-3.

49 Swartz C, Sherman A. The treatment of tricyclic antidepressant overdose with repeated charcoal. I Clin Psychopharmacol 1984;4:336-40.

50 Ilett KF, Hackett LP, Dusci LJ, et al. Disposition of dothiepin after overdose: effects of repeated dose activated charcoal. Ther Drug Monit 1991;13:485-9.

51 Brown TCK, Barker GA, Dunlop ME, et al. The use of sodium bicarbonate in the treatment of tricyclic sodium bicarbonate in the treatment of tricyclic 1973;1:203-10

52 Sasyniuk BI, Jhamandas V, Valois M. Experimental amitriptyline intoxication: treatment of cardiac toxicity with sodium bicarbonate. Ann Emerg Med 1986;15:1052-9.

53 Hoffman JR, Votey SR, Bayer M, et al. Effect of hypertonic sodium bicarbonate in the treatment of moderate to severe
cyclic antidepressant overdose. Am f Emerg Med 1993;11: 336-41.

54 Kingston ME. Hyperventilation in tricyclic antidepressant poisoning. Crit Care Med 1979;7:550-1.

55 Bessen HA, Neimann JT. Improvement of cardiac conduction after hyperventilation in tricyclic antidepressant overdose. F Clin Toxicol 1985;23:537-46.

56 Wrenn K, Smith BA, Slovis CM. Profound alkalemia during treatment of tricyclic antidepressant overdose: a potential of combined hyperventilation and intraventaus bicarbonate. Am f Emerg Med 1992;10:553-5.
57 Levitt MA, Sullivan JB, Owens SM, et al. Amitriptyline plasma protein binding: effect of plasma $\mathrm{pH}$ and relevance to clinical overdose. Am f Emerg Med 1986;4:121-5.

58 Brown TCK. Sodium bicarbonate and tricyclic antidepressant poisoning. Lancet 1977;1:375.

59 Pentel P, Benowitz N. Efficacy and mechanism of action of sodium bicarbonate in the treatment of desipramine toxicity of rats. F Pharmacol Exp Ther 1984;230:12-19.

60 Molloy DW, Penner SB, Rabson J, et al. Use of sodium bicarbonate to treat tricyclic antidepressant-induced arrhythmias in a patient with alkalosis. Can Med Assoc f 1984;130:1457-9.

61 McCabe JL, Cobaugh, Menegazzi JJ, et al. Experimental tricyclic antidepressant toxicity: a randomised, controlled comparison of hypertonic saline solution, sodium bicarbonate and hyperventilation. Ann Emerg Med 1998;32:32933.

62 Sasyniuk BI, Jhamandas V. Mechanism of reversal of toxic effects of amitriptyline on cardiac purkinje fibers by sodium bicarbonate. F Pharmacol Exp Ther 1984;231:387-94.

63 Brown TCK. Tricyclic antidepressant overdosage: experimental studies on the management of circulatory complications. Clin Toxicol 1976;9:255-72.

64 Knudsen K, Abrahamsson J. Effects of magnesium sulfate and lidocaine in the treatment of ventricular arrhythmias in experimental amitriptyline poisoning in the rat. Crit Care Med 1994;22:494-8.

65 Boehnert M, Lovejoy F. The effect of phenytoin on cardiac conduction and ventricular arrhythmias in acute tricyclic antidepressant overdose. Vet Hum Toxicol 1985;28:297.

66 Hagerman GA, Hanashiro PK. Reversal of tricyclic antidepressant induced cardiac conduction abnormalities by phenytoin. Ann Emerg Med 1981;10:82-6.

67 Mayron R, Ruiz E. Phenytoin:does it reverse tricyclic antidepressant induced cardiac conduction abnormalities? Ann Emerg Med 1986;15:876-80.

68 Freeman JW, Mundy GR, Beattie RR, et al. Cardiac abnormalities in poisoning with tricyclic antidepressant. $B M \mathcal{F}$ 1969;2:610-11.

69 Sener E, Gabe S, Henry J. Response to glucagon in imipramine overdose. Clin Toxicol 1995;33:51-3.

70 Knudsen K, Abrahamsson J. Magnesium sulphate in the treatment of ventricular fibrillation in amitriptyline. Eur Heart f;18:881-2.

71 Knudsen K, Abrahamsson J. Effects of magnesium sulfate and lidocaine in the treatment of ventricular arrhythmias in experimental amitriptyline poisoning in the rat. Crit Care Med 1994;22:494-8.

72 Pentel P, Peterson CD. Asystole complicating physostigmine treatment of tricyclic antidepressant overdose. Ann Emerg Med 1980;9:588-90.

73 Knudson K, Heath A. Effects of self poisoning with maprotiline. $B M \mathcal{F}$ 1984;288:601-3.

74 Buchman A, Dauer J, Geiderman J. The use of vasoactive agents in the treatment of refractory hypotension seen in tricyclic antidepressant overdose. F Clin Psychopharmacol 1990;10:409-13.

75 Teba L, Scheibel F, Dedhia H, et al. Beneficial effect of norepinephrine in the treatment of circulatory shock caused by tricyclic antidepressant overdose. Am f Emerg Med 1988;6:566-8.

76 Knudsen K, Abrahamsson J. Effects of epinephrine and norepinephrine on haemodynamic parameters and arrhythmias during a continuous infusion of amitriptyline in rats. Clin Toxicol 1993;31:461-71.

77 Knudsen K, Abrahamsson J. Epinephrine and sodium bicarbonate independently and additively increase survival in experimental amitriptyline poisoning. Crit Care Med 1997;25:669-74.

78 Williams JM, Hollingshed MJ, Vasilakis A, et al. Extracorporeal circulation in the management of severe tricyclic antidepressant overdose. Am f Emerg Med 1994;12:456-8. 9 Goodwin DA, Lally KP, Null DM. Extracorporeal mem-
brane oxygenation support for cardiac dysfunction from brane oxygenation support for cardiac dysfunction from
tricyclic antidepressant overdose. Crit Care Med 1993;21: 625-7.

80 Larkin GL, Graeber GM, Hollingsed MJ. Experimental amitriptyline poisoning:treatment of severe cardiovascular toxicity with cardiopulmonary bypass. Ann Emerg Med 1994;23:480-6.

81 Orr D, Bramble M. Tricyclic antidepressant poisoning and prolonged external cardiac massage during asystole. BMF 1981;283:1107-8.

82 Ramsay ID. Survival after imipramine poisoning. Lancet 67 ;ii: $1308-9$

83 Southall DP, Kilpatrick SM. Imipramine poisoning:survival of a child after prolonged cardiac massage. BMF 1974;4:

84 Beaubien A, Carpenter D, Mathieu L, et al. Antagonism of imipramine poisoning by anticonvulsants in the rat. Toxicol Appl Pharmacol 1976;38:1-6.

85 Brunn GJ, Keyler DE, Pond SM, et al. Reversal of desipramine toxicity in rats using drug specific antibody Fab fragments:effects on hypotension and interaction with sodium bicarbonate. F Pharmacol Exp Ther 1992;260:13929.

86 Pentel PR, Scarlett W, Ross CA, et al. Reduction of desipramine cardiotoxicity and prolongation of survival in rats using polyclonal drug specific antibody Fab fragments. Ann Emerg Med 1995;126:334-41.

87 Heard K, O'Malley GF, Dart RC. Treatment of amitriptyline poisoning with ovine antibody to tricyclic antidepressants. Lancet 1999;354:1614-15. 
88 Heath A, Wickstrom I, Martensson E, et al. Treatment of antidepressant poisoning with resin hemoperfusion. Hum antidepressant poison

89 Crome P, Hampel G, Vale JA, et al. Haemoperfusion in treatment of drug intoxication. BMF 1978;1:174.

90 Bailey RR, Sharma JR, O'Rourke J, et al. Haemodialysis and forced diuresis for tricyclic antidepressant poisoning. $B M f$ $1974 ; 4: 230-1$

91 Tokarski G, Young M. Criteria for admitting patients with tricyclic antidepressant overdosage. $\mathcal{F}$ Emerg Med 1988;6: 121-4.

92 Banahan B, Schelkun P. Tricyclic antidepressant overdosage: conservative management in a community hospital with cost-saving implications. $f$ Emerg Med 1990;8:451-4.

93 Pentel P, Sioris L. Incidence of late arrhythmias following TCA overdose. Clin Toxicol 1981;8:543-8.
94 Fasoli R, Glauser F. Cardiac arrhythmias and ECG abnormalities in TCA overdose. Clin Toxicol 1981;18:15563.

95 Goldberg RJ, Capone RJ, Hunt JD. Cardiac complications following tricyclic antidepressant overdose. $\mathcal{F A M A ~ 1 9 8 5 ;}$ 254:1772-5.

96 Barnes RJ, Kong SM, Wu RWY. Electrocardiographic changes in amitriptyline poisoning. BMF 1968;3:222-3.

97 Freeman JW, Mundy GR, Beattie RR, et al. Cardiac abnormalities in poisoning with tricyclic antidepressant. BMf 1969;2:610-11

98 Pentel P, Benowitz N. Tricyclic antidepressant poisoningmanagement of arrhythmias. Med Toxicol 1986;1:101-21.

99 Emerton D. British poisons centres' advice concerning dothiepin overdosage in young children. 7 Accid Emerg Med 1997;14:200. 